\title{
Implementation of Ziegler Nichols Tuning Method on PID Controller for DC-DC Boost Converter used in Horizontal Axis Wind Generator
}

\author{
Esperanza E. Chua ${ }^{1+}$, Conrado F. Ostia, Jr. ${ }^{1+}$, Charlz Alddin E. Andres ${ }^{1}$, Christian Lesley M. \\ Carabit ${ }^{1}$, Elaine Grace A. Dichoso ${ }^{1}$ and Michael John A. Villanueva ${ }^{1}$ \\ ${ }^{1}$ School of Electrical, Electronic and Computer Engineering, Mapua University, Manila, Philippines
}

\begin{abstract}
Growing demand of using wind turbines for harnessing energy has become a trend throughout the years. This study proposes the use of DC-DC boost converter tuned with Ziegler Nichols PID controller for stable maximum power output of the horizontal axis wind turbine. Developing the design of the turbine has been tackled; however, is not the only solution. It is known that varying wind affects the performance of the wind turbine. However, application of the tuned DC-DC boost converter provides various solutions to this problem and one factor that can maintain the turbine to its maximum operation. Ziegler Nichols tuned PID learns from the error given by the wind turbine and corrects it thus getting the maximum voltage. It is also known for faster transient response but has high overshoot. Testing the turbine with varying wind speed, the results showed that it reacts, corrects and boost the voltage for a short period of time using this Ziegler Nichols Tuning parameter.
\end{abstract}

Keywords: Ziegler Nichols, PID, DC-DC Boost Converter, Horizontal Axis Wind Turbine

\section{Introduction}

In recent years, researches, development and innovations of wind turbine has been an attention catcher because of its issue of taking so much land while producing less power than other renewable sources. With the increase capacity of wind turbines, its stability and reliability of control are still important aspects in achieving good performance. As a result, variable speed wind turbine has been introduced. For a certain type of blade of a wind turbine, there is the best angle for which it will produce maximum power. However, varying wind speed limits its maximum results. DC-DC booster converter will be able to keep the turbine in its maximum voltage output and keep it stable.

Boost converters are converters that step up the voltage in such a way that the output voltage will always have a greater value than the input voltage. DC-DC converter's output voltage regulation is usually achieved by controlling the energy that flows from the source through the load, which can be adjusted by the durations of the cycle with the help of PID [1]. Wind energy conversion systems (WECS) are designed to convert wind energy into mechanical power. WECS includes wind turbines and generators. WECS output voltage depends on the wind speed which is not constant. Thus, a power conversion unit is needed to maintain the output voltage of WECS stable or constant [2]. DC-DC converters are responsible for the conversion of direct current voltage from one to other level in which the output voltage has to be controlled with respect to disturbances. DC-DC converters provides steady output voltage for broad range of resistances and input voltage. Since it has many positive properties, the DC-DC converters remain incomparable part of renewable energy power plants [3]. PID controller is mostly used to neutralize the error arising from the discrepancy between the set point and feedback voltage in power converters design because of its simplicity and usefulness [4]. PID controllers are most likely used to converters to enhance their productivity. Boost like converters provide more drawbacks on their control part because of their non-minimum phase characteristics

\footnotetext{
+ Corresponding author. Tel.: + 639232097574

E-mail address: cfostia@mapua.edu.ph, eechua@mapua.edu.ph
} 
[5].

The main objective of this study is to implement a Ziegler Nichols tuning method on a PID controller for DC-DC boost converter using a microcontroller to stabilize the voltage output to its maximum at different wind speeds. Specifically, it aims to design and build a boost DC-DC converter with integrated PID controller for HAWT, calibrate the integrated measurement systems, tune the PID controller with Ziegler Nichols, and evaluate the performance of the wind turbine with DC-DC boost converter in terms of the output voltage.

\section{Methodology}

\subsection{Design Process Flowchart}

The researchers will be performed according to the process shown in Figure 1. The design will be implemented through (1) Construction of a small-scale wind turbine that makes use of PID controller as its main control (2) Calibration of the measurement system before the testing proper. The testing of the Aerostat based vertical wind turbine will be done at Mapua University using the Gunt Hamburg HM170 wind tunnel. (3) The gathering of data such as power and voltage generated at different wind speeds. (4) Interpretation of the data collected will be done including conclusions and recommendations for improvement of the study. (5) Evaluation of the performance of the wind turbine.

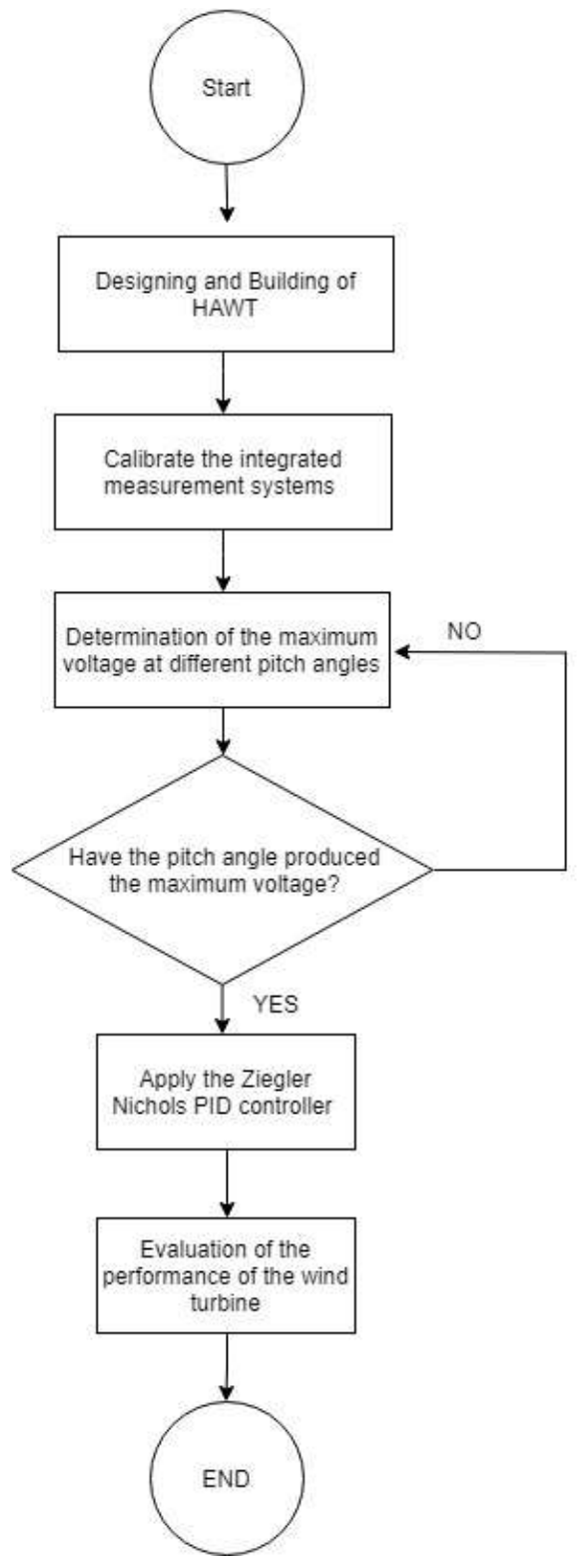

Fig. 1: Design Process Flowchart. 


\subsection{Horizontal Wind Axis Turbine}

The mechanism is inspired by the slider-crank mechanism. It is combined with a shaft which acts as the push pull mechanism to make the 3 blades synchronize to each other. A wind turbine with blades greater than 3 would make more wind resistance, reducing the generation of electricity. Hence, it will become less efficient [1]. A motor exerts a force that makes the shaft move forward or backward and rotates the blade which means this concept protects the wind turbine from being damaged by varying wind speed, thus producing maximum power. The sensors connected to the generator and turbine system transmit its data to a laptop through an Arduino IDE. The wind tunnel will provide the simulation of wind speeds at certain heights while the laptop connected to the electronic box allows real-time monitoring as well as data logging of voltage, current, wind speed and rpm readings of the entire system.
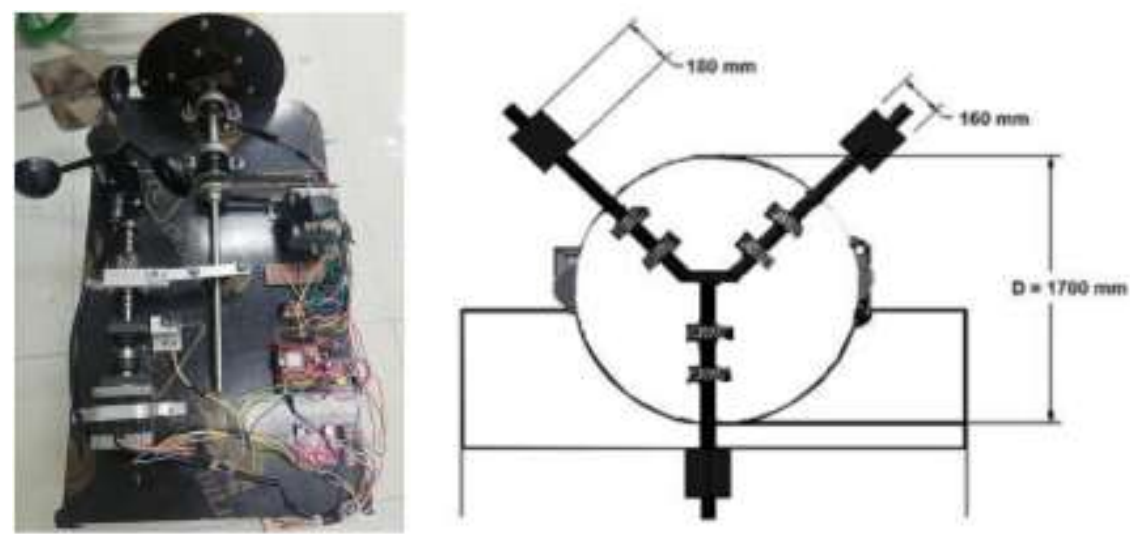

Fig. 2: Horizontal Wind Turbine.

\subsection{Ziegler-Nichols Tuning Parameter}

Integrating PID to the tuning method: Ziegler-Nichols, $u(t)$ from Eq. (1) will be used as the formula for the correction factor and the classic Ziegler-Nichols tuning parameters which is stated at Eq. (2) will be substituted. Usually a guess from 0 to a certain set point for the gain $\mathrm{Kp}$ will be given until getting the ultimate gain which is $\mathrm{Ku}$ but since there is an input from the voltage sensor and a reference of the voltage of the generator then using their ratio of the output to the input to get Kp. The program then observes the frequency namely $\mathrm{Fu}$ at which the phase passes through 5 volts. Period of oscillation, Tu, refers to the inverse of this frequency. Lastly, the program will check the plant gain Kc that arises at the critical oscillation frequency $\mathrm{Fu}$. The inverse of this is the gain margin $\mathrm{Ku} . \mathrm{Ku}$ and $\mathrm{Pu}$ then is substituted to the Classic Ziegler-Nichols then substituted to the correction factor.

$$
\mathrm{V}_{\text {new }}=\mathrm{K}_{\mathrm{p}} \mathrm{V}_{\text {error }}+\mathrm{Ki} \sum_{\mathrm{k}=0}^{\mathrm{n}} \mathrm{v}_{\text {total error }}+\mathrm{Kd} * \frac{\left(\mathrm{V}_{\text {error }}-\mathrm{V}_{\text {last error }}\right)}{\mathrm{T}}
$$

To integrate the PID to Arduino, the correction factor is then converted to its discrete-time form where:

$$
\mathrm{V}=\mathrm{V}_{\text {setpoint }}-\mathrm{V}_{\text {sensed output }}
$$

\subsection{Boost Converter}

A DC-DC boost converter is simply composed of four parts: Inductor, Capacitor, Diode and Electronic switch. The boost converter can operate at two different states depending on the energy stored in the capacitor and how long the is the switching period [2]. 


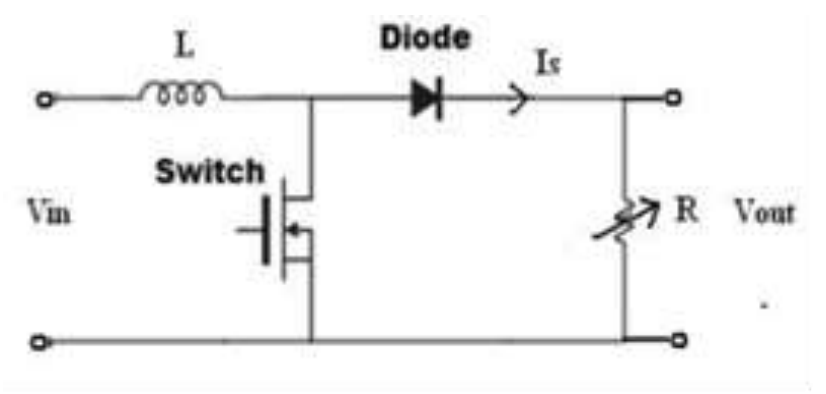

Fig. 3: Boost Converter Circuit.

Figure 3 shows the basic circuit of a boost converter. Here, $\mathrm{R}$ refers to the resistor which is considered to be the load, $\mathrm{L}$ is the inductor and Is is the current flowing through the circuit. Switch is activated by the pulse generated by the wind turbine. The switch remains on during Ton cycle and off during Toff cycle depending on the cycle duty.

\subsection{Control System}

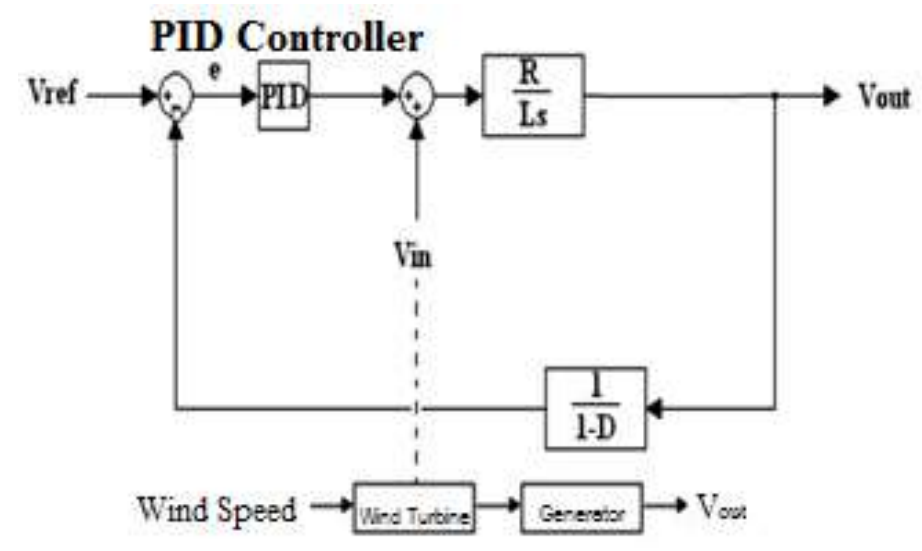

Fig. 4: Control System.

To acquire the objective performance of converter, it is needed to both determine and keep the output voltage at required voltage level. Hence, there is a need to use feedback loop into the system that is shown in figure 4. This shows eq. (3) Vout is given to the generator. The output of the generator is compared to Vref which is given to the PID controller then it is added Vin which is given by the wind turbine. Setting Vref equal to 0, comes up with Eq. (4). Simplifying the equations leads to Eq. (5) which is the transfer function of the closed loop system.

Based from Figure 5,

$$
\mathrm{V}_{\text {out }}=\left(\frac{\mathrm{R}}{\mathrm{L}^{*} \mathrm{~s}}\right)\left\lfloor\mathrm{V}_{\text {in }}+\left(\mathrm{K}_{\mathrm{p}}+\frac{\mathrm{K}_{\mathrm{i}}}{\mathrm{s}}\right) * \mathrm{e}\right\rfloor
$$

Setting Vref $=0$

$$
\begin{gathered}
\mathrm{V}_{\text {out }}+\left[\left(\frac{\mathrm{R}}{\mathrm{L} * \mathrm{~s}}\right) *\left(\mathrm{~K}_{\mathrm{p}}+\frac{\mathrm{K}_{\mathrm{i}}}{\mathrm{s}}\right) *\left(\frac{1}{1-\mathrm{D}}\right) * \mathrm{~V}_{\text {out }}\right]=\mathrm{V}_{\text {in }} \\
\quad \frac{\mathrm{V}_{\text {out }}}{\mathrm{V}_{\text {in }}}=\frac{\frac{\mathrm{R}}{\mathrm{L} * \mathrm{~s}}}{\left[1+\left\{\left(\frac{\mathrm{R}}{\mathrm{L} * \mathrm{~s}}\right) *\left(\mathrm{~K}_{\mathrm{p}}+\frac{\mathrm{K}_{\mathrm{i}}}{\mathrm{s}}\right) *\left(\frac{1}{1-\mathrm{D}}\right)\right\}\right]}
\end{gathered}
$$

(Transfer Function of the closed loop system)

\section{Results and Discussion}

\subsection{Calibration of Sensors}

Table 1 shows the T-test results of different sensors to ensure the gathered data is accurate. The sensors used are tested against a device of calibration standard and of known accuracy. 
Table 1: T-test values for different sensors.

\begin{tabular}{|c|c|c|}
\hline Sensors & Critical Value & T Value \\
\hline Wind Sensor & 2.179 & 0.3554 \\
\hline Current Sensor & 2.31 & 0.222 \\
\hline Voltage Sensor & 2.31 & 0.11 \\
\hline Hall-Effect Sensor & 2.31 & 0.063 \\
\hline
\end{tabular}

After gathering the data for the calibrations, a T-test was used to compare the results from table 1 with a null hypothesis to use as a proof that the differences between the data are a result of chance. Since the Tvalue is lower than the critical value, the hypothesis is considered null; therefore, there is no significant statistical difference between the samples of the sensors used and the device with known accuracy.

\subsection{Tuning PID Controller with Ziegler Nichols}

After tuning the PID with Ziegler Nichols method, it can be found that the values of $\mathrm{Kp}, \mathrm{Ki}$ and $\mathrm{Kd}$ are given below.

$\mathrm{Kd}=0.306, \mathrm{Ki}=3.4$ and $\mathrm{Kd}=0.306$. Applying these values to the PID controller with a closed system and simulate it in the Arduino application will result and have a response shown in figure 5. As shown from the figure below, it can be seen that the steady state error gradually decreases until it diminishes but it has high oscillation.

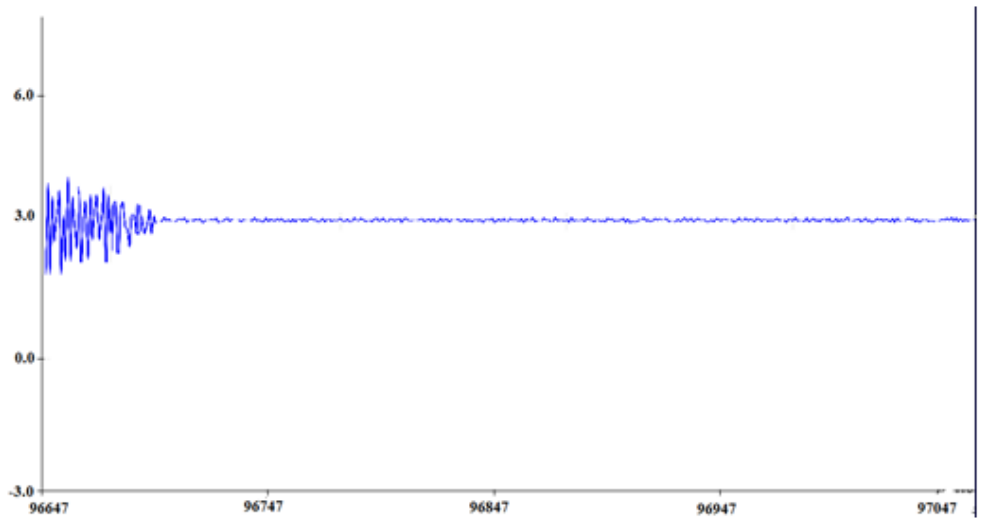

Fig. 5: Output Response of Ziegler Nichols Tuning

\subsection{Application of DC-DC Booster on the Wind Turbine}

Table 2 shows the effect of the DC-DC booster on the wind turbine. The wind turbine is also tested on 10 different wind speeds. Table 2 also shows how the output voltage can be vary by using a PID controller on the booster.

Table 2: comparison for output voltages.

\begin{tabular}{|c|c|c|c|c|}
\hline \multirow{2}{*}{$\begin{array}{c}\text { Wind } \\
\text { Speed } \\
(\mathrm{m} / \mathrm{s})\end{array}$} & $\begin{array}{c}\text { Voltage } \\
\text { Generated } \\
\text { (Volts) }\end{array}$ & $\begin{array}{c}\text { Without } \\
\text { Booster }\end{array}$ & $\begin{array}{c}\text { With } \\
\text { Booster, } \\
\text { Without } \\
\text { PID }\end{array}$ & $\begin{array}{c}\text { With } \\
\text { Booster, } \\
\text { With PID }\end{array}$ \\
\hline 15.4 & 0.85 & 0.85 & 4.91 & 4.98 \\
\hline 15.96 & 1.02 & 1.02 & 4.91 & 4.99 \\
\hline 16.52 & 1.45 & 1.45 & 4.92 & 4.98 \\
\hline 17.08 & 1.99 & 1.99 & 4.93 & 4.97 \\
\hline 17.64 & 2.35 & 2.35 & 4.92 & 4.99 \\
\hline 18.2 & 2.96 & 2.96 & 4.9 & 4.98 \\
\hline 18.76 & 3.46 & 3.46 & 4.91 & 4.99 \\
\hline 19.32 & 3.86 & 3.86 & 4.93 & 5 \\
\hline 19.88 & 4.08 & 4.08 & 4.93 & 4.98 \\
\hline 20.44 & 4.95 & 4.95 & 4.94 & 4.97 \\
\hline
\end{tabular}


Figure 6 shows the comparison of the output voltages of the wind turbine without booster, with booster and with Ziegler Nichols tuned PID booster. As seen from the graph the wind turbine with Ziegler Nichols tuned PID booster produces the greatest output voltage and nearest to the maximum voltage which is $5 \mathrm{~V}$.

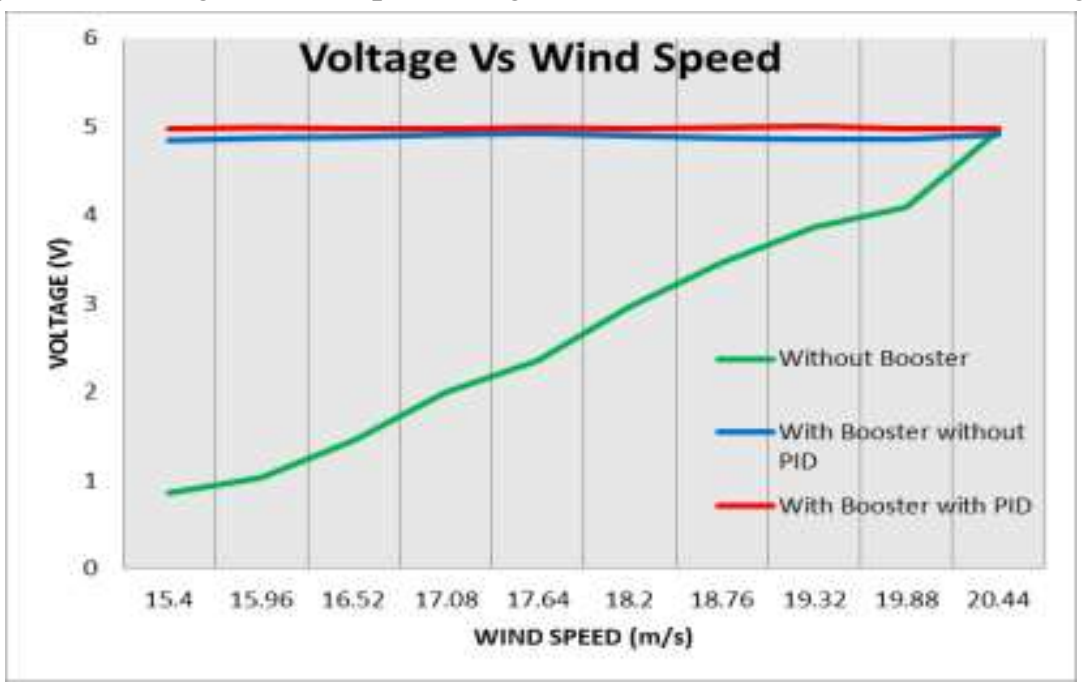

Fig. 6: Comparison for Output Voltage

\subsection{Conclusion}

The researchers were able to integrate a PID controlled DC-DC boost converter on a small-scale Horizontal Wind Axis Turbine. This was done by calibrating the sensors to be used for the experiment proper. As per result, the voltage produced was larger than the output of the wind turbine itself because of the boost converter. The result also shows that the voltage produced by the wind turbine was not stable. But with the integration of the PID Controller tuned by the Ziegler Nichols Method, we can see that the voltage produced was able to produce a steady voltage close or equal to $5 \mathrm{~V}$.

\subsection{Recommendation}

The researchers recommend using other methods not only in PID for a more learning curve for the system. In order to validate more specific results, try to conduct simulations with a more erratic wind speed. Also, include wind speeds in the simulations that would cause the voltage beyond $5 \mathrm{~V}$ and try to apply buckboost converter. The researchers also recommend doing this in a larger scale wind turbine. Other equipment's for the controller is preferred if this is to be done on a larger scale i.e. better processor or microcontroller, alternative to boost converter, bigger generator, etc. The researchers also recommend that a vacuum wind tunnel is used for better results.

\section{References}

[1] Mitra, L., Swain, N. Closed loop control of solar powered boost converter with PID controller. IEEE International Conference on Power Electronics Drives and Energy System. 2014.

[2] Porselvi T., \& Ranganath M. Wind Energy Conversion System with Boost Converter and CHB MLI with single DC input. International Journal of Engineering and Technology 6(1):138-145. 2014.

[3] Almawlawe. M., \& Kovandzic M. Modified Ziegler-Nichols Method for Tuning a PID Controller of Buck-Boost converter. International Journal of Advanced Engineering Research and Science. 3. 20-26. 2016.

[4] Ibrahim, O., \& Yahaya N. Comparative Studies of PID Controller Tuning Methods on a DC-DC Boost Converter. International Conference on Intelligent and Advanced Systems. 2016.

[5] Abbas, G., Samad, M. A., Gu, J., Asad, M. U., Farooq, U. Set-point tracking of a dc-dc boost converter through optimized PID controllers. IEEE Canadian Conference on Electrical and Computer Engineering. 2016. 